\title{
The protective role of copper nicotinate and vitamin $E$ against neem seed oil induced oxidative stress and histopathological changes in Nile Tilapia \\ (Oreochromis niloticus, Linnaeus, 1758)
}

\author{
Ashraf A. El-Badawi ${ }^{1,2}$, Alkhateib Y. Gaafar ${ }^{3}$, Hossam H. Abbas ${ }^{3}$ and \\ Mohammad M. N. Authman ${ }^{3}$ \\ 1- Central Laboratory for Aquaculture Research, Abbassa, Abo-Hammad, Sharkia, \\ Egypt. \\ 2- Biological Department,University College,Umm Al-Qura University,Kingdom of \\ Saudi Arabia. \\ 3- Hydrobiology Department, National Research Centre, Dokki 12622, Giza, Egypt.
}

\begin{abstract}
The aim of the current investigation was to evaluate whether neem (Azadirachta indica) seeds oil (NO) induced changes on some oxidative indicators and histopathological alterations in tissues of Oreochromis niloticus fish and the possible protective effects of copper nicotinate $(\mathrm{CN})$ and vitamin $\mathrm{E}$ on neem oil-induced changes. Fish were divided into 8 groups and treated with $\mathrm{NO}$ alone or in combination with $\mathrm{CN}$, vitamin $\mathrm{E}$ and clean water. $\mathrm{NO}$ interfered with the antioxidant defense system of $O$. niloticus, as there was a decrease in GST, CAT and SOD activities in all studied organs as compared to control group. These alterations in antioxidants activities were accompanied with the occurrence of histological lesions and damage in gills, liver and posterior kidney tissues. The addition of $\mathrm{CN}$ and Vitamin $\mathrm{E}$ in fish diets could protect the fish $O$. niloticus against NO-induced oxidative damage and histopathological changes showing recovery of fish organs. It was concluded that although botanical pesticides are being considered as less toxic/safe, but it may provoke deleterious changes in vital organs of the fish. Hence, precautions must be taken into account when botanicals are being used in fish production facilities.
\end{abstract}

Keywords: Oreochromis niloticus, neem seed oil, oxidative stress, histopathology changes, copper nicotinate, vitamin $\mathrm{E}$.

\section{INTRODUCTION}

In view of the environmental problems caused by the use of synthetic pesticides and other chemicals and the growing need for alternative methods of pest control that minimize this damage, also, to produce fish free from any chemicals of public health hazards, there has been extensive research on pest control by substances from plants as alternatives to synthetic chemical pesticides (Winkaler et al.,2007 and Mousa et al.,2008). One of the most promising medicinal plants is Neem (Azadirachta indica A. Juss) having a wide spectrum of biological activity (Mousa et al., 2008). Neem tree is a large evergreen tree with edible fruits and aromatic leaves, found in most tropical countries (Talpur and Ikhwanuddin, 2013). Every part of neem tree have been known to possess a wide range of pharmacological properties, especially as antibacterial, antifungal, antiviral, antiulcer, antifeedant, repellent, pesticidal, molluscicidal, ecdysone inhibitor and sterilant and is thus commercially exploitable (Biswas et al., 2002).

Neem has been used successfully in aquaculture systems to control fish predators (Dunkel and Richards, 1998 and Kumar et al., 2010). Martinez (2002) stated that aqueous extract of neem leaves and other neem-based products have been 
extensively used in fish-farms as alternative for the control of fish parasites and fish fry predators such as dragon-fly larvae. Although neem extract is considered target specific and of low toxicity towards non-target aquatic life (Oti and Ukpabi, 2005), water extracts of the bark of the neem plant caused respiratory problems in redbelly tilapia, Tilapia zilli (Gervais) (Omoregie and Okpanachi, 1997), while long exposure to low concentrations of the crude extract of $A$. indica delayed the growth of this cichlid fish (Omoregie and Okpanachi, 1992). Recently, it was observed that the neem-based pesticide, Achook, was toxic to zebrafish (Ansari and Sharma, 2009).

Exposure to xenobiotics (i.e. pesticides) or toxic chemical pollutants may produce an imbalance between the endogenous and exogenous reactive oxygen species (ROS) and can subsequently induce a decrease in antioxidant defenses or cause oxidative damage outright in organisms (Valavanidis et al., 2006 and Özkan et al., 2012). ROS induce damage on most biomolecules, namely lipids, proteins and DNA (Ballesteros et al., 2009). Endogenous enzymatic and non-enzymatic antioxidants are essential for the conversion of ROS to harmless metabolites as well as to protect and restore normal cellular metabolism and functions (Bebe and Panemangalore, 2003). Defence systems that tend to inhibit ROS formation include the antioxidant enzymes such as superoxide dismutase (SOD), catalase (CAT), glutathione peroxidase (GSH-Px) and glutathione-S-transferase (GST), in vivo could clear ROS, thereby preventing oxidative stress (Ahmad et al., 2000). Like other organisms, fish combat elevated levels of ROS with protective ROS scavenging enzymes (Craig et al., 2007). Thus, the induction of these enzymes is considered beneficial and provides useful indicator of exposure to oxidative stress-inducing chemical contaminants in fish (Van der Oost et al., 2003 and Pereira et al., 2013).

From the last decade until now, little studies used chelating agents as copper nicotinate $(\mathrm{CN})$ and copper glycinate $(\mathrm{CG})$ complexes on recovery of some diseases, which accompanied with severe propagation of reactive oxygen species (ROS). Copper complex is antiapoptotic, control cellular differentiation and proliferation, superoxide dismutase (SOD)-mimetic free radical scavengers (Salahy, 2011). In mammals, it is found that copper complexes were anti-inflammatory, healing promoter, analgesic, antipyretic, radioprotectant, anticonvulsant, antiasthmatic, antimicrobial, anticancer, anti-carcinogenetic, angiogenic and antimutagenic agents $(\mathrm{Hu}, 1998)$. It was found that the addition of copper nicotinate $(\mathrm{CN})$ in fish diets could improve the metabolic disturbances in Clarias gariepinus fish and protect the treated fish against mercuric chloride-induced oxidative damage (Al-Salahy, 2011).

Vitamin E ( $\alpha$-tocopherol) is important for many physiological processes in animals. Vitamin $\mathrm{E}$ is a natural biological antioxidant component of the membrane lipid bilayer (Kan et al 2012). which prevents toxic peroxides from accumulating and protects cells from damaging effects of free radicals generated following pesticides exposure (Kan et al., 2012). Vitamin E also ensures the stability and integrity of biological membranes (Méndez et al., 2002).

To the best of our knowledge, the literature on the toxic effects of neem seeds oil extract on fish is scanty (Hassanein and Okail, 2008) and there is no existing report on its alterations on the organs and healthy status of Nile tilapia (Oreochromis niloticus). We preferred to use $O$. niloticus fish as a test model species, mainly because tilapia is the most important aquaculture fish in Egypt (Abbas et al., 2007) and O. niloticus is ecologically and commercially important and the most popularly delicacy relished consumed fish in Africa and Egypt (Authman et al., 2012). Also, $O$. niloticus belongs to one of the most important groups of fish, being recognized as good biological models, due to its easy handling, culture, and maintenance in the 
laboratory, and for studying possible adaptations to pollutants in toxicological studies (Cengiz et al., 2012 and Garcia-Santos et al., 2006).

The aim of the present study was (a) to evaluate whether neem seeds oil induced changes on some oxidative indicators (enzymatic [superoxide dismutase (SOD) and catalase (CAT)] and non-enzymatic (GSH) antioxidants) and histopathological alterations in tissues of $O$. niloticus and (b) to investigate the possible protective effects of copper nicotinate $(\mathrm{CN})$ and vitamin $\mathrm{E}$ on neem oil-induced changes.

\section{MATERIALS AND METHODS}

\section{Fish specimen collection and maintenance}

Healthy fish Tilapia (Oreochromis niloticus) of both sexes were collected from the nursery ponds of El-Jomoom Fish Farm, Jeddah, Kingdom of Saudi Arabia in month of June 2012. On arrival at the laboratory, the fish was selected and the fishes with external abnormalities such as damaged fins and/or swelling body, unnatural colors and wounded fish were avoided. Nile tilapia fish (O. niloticus) used in this study was with a mean weight of $32.5 \pm 4.2 \mathrm{~g}$ and a mean length of $12.4 \pm 1.6 \mathrm{~cm}$. The experimental fishes were reared in well aerated; air compressor was used for oxygenation of water; four glasses tanks $(50 \times 85 \times 70 \mathrm{~cm})$ containing de-chlorinated tap water and acclimatized for 7 days, before being used in the experimental study. Feeding was done twice daily using commercial dry pelleted diet pellets of $2.5 \mathrm{~mm}$ at rate of $3 \%$ of the fish body weight. Food ratio of dry weight composed of $60 \%$ protein, $18 \%$ fat, $6 \%$ carbohydrates and $11 \%$ ashes. The water in aquaria was changed daily to avoid metabolite accumulations.

The water temperature and $\mathrm{pH}$ values were measured using Hanna Instrument HI 2210 Benchtop $\mathrm{pH}$ meter W/Temperature compensation meter (USA), whereas dissolved oxygen (DO) concentrations were measured using Portable oxygen meter (DO-980) (Henan Wheat Import And Export Co. Ltd, China). Detailed routine water quality parameters monitored daily during the present study were as follows: dissolved oxygen concentrations ranged from 6.3 to $6.8 \mathrm{mg} \mathrm{l}^{-1}$, the ambient water temperature range was $21-23^{\circ} \mathrm{C}$ and $\mathrm{pH}$ range was (7.1- 7.4).

\section{Test chemicals}

\section{Neem seed oil (NO)}

Neem seed oil was purchased from Trifolio-m GmbH Company, Germany. The lethal conservation $\left(\mathrm{LC}_{50}\right)$ of neem oil for the tilapia was $1124.6 \mathrm{ppm}$ according to the method of Jacobson, 1995. Therefore, the neem oil dose used in this experiment were $1 / 10 \mathrm{LC}_{50}(112.5 \mathrm{ppm}$; i.e. $112.5 \mathrm{mg} / \mathrm{l})$. Before use, the neem oil was emulsified by using emulsifier agent (SiSi-6) and the emulsifiable concentrate was 50\%.

\section{Copper nicotinate $(\mathrm{CN})$}

The copper (I)-Cl-(nicotinic acid) $)_{2}$ complex was prepared as described by (Goher, 1987). Copper nicotinate (Cu-N complex) doses used in this experiment were: the low CN1 (15 mg/100 g wet food) and high CN2 (25 mg/100 g wet food) doses were prepared by mixing $\mathrm{CN}$ with wet food.

\section{Vitamin E}

Vitamin E ( $\alpha$-tocopherol acetate) was supplied by Sigma-Aldrichs. In order to prepare the vitamin E-supplemented diet ( $\alpha$-tocopherol content $100 \mathrm{mg} / \mathrm{kg}$ wet wt), the commercial pellet diet was milled by a feed producer, the vitamin-E added and the diets repelletized in a pellet mill. 


\section{Experimental design and treatments}

The study was performed in duplicate to verify accurate results. Fish were randomly divided into eight groups in eight glass aquaria $(100 \mathrm{~L}$ each). Design of the experiment was conducted in table (1) as follows:

* Group I (n: 15), the control group, which had no exposure. This group was fed with control diet.

* Group II (n: 15), this group was treated with Neem oil (NO) $\left(1 / 10 \quad \mathrm{LC}_{50}=112.5\right.$ $\mathrm{mg} / \mathrm{l})$ for 3 weeks and then fish were sacrificed and dissected. This group was fed with control diet.

* Group III (n: 15), following 3 weeks of normal ambient water exposure, this group was fed for 1 week only with CN1 (15 mg/100gm wet food).

* Group IV (n: 15), following 3 weeks of normal ambient water exposure, this group was fed for 1 week only with CN2 (25 mg/100gm wet food).

* Group V (n: 15$)$, this group was treated with Neem oil (NO) $\left(1 / 10 \mathrm{LC}_{50}=112.5\right.$ $\mathrm{mg} / \mathrm{l})$ for 3 weeks and then fed for 1 week only with CN1 $(15 \mathrm{mg} / 100 \mathrm{gm}$ wet food).

* Group VI (n: 15), this group was treated with Neem oil (NO) $\left(1 / 10 \mathrm{LC}_{50}=112.5\right.$ $\mathrm{mg} / \mathrm{l})$ for 3 weeks and then fed for 1 week only with CN2 $(25 \mathrm{mg} / 100 \mathrm{gm}$ wet food).

* Group VII (n: 15), this group was treated with Neem oil (NO) $\left(1 / 10 \mathrm{LC}_{50}=112.5\right.$ $\mathrm{mg} / \mathrm{l})$ for 3 weeks and then fed for 1 week only with vitamin E-supplemented diet $(100 \mathrm{mg} / \mathrm{kg}$ wet diet). Vitamin $\mathrm{E}$ was used as standard antioxidant drug.

* Group VIII (n: 15$)$, this group was treated with Neem oil (NO) $\left(1 / 10\right.$ LC $_{50}=112.5$ $\mathrm{mg} / \mathrm{l})$ for 3 weeks and then followed by normal clean water for 1 week. This group was fed with control diet.

Table 1: Design of fish groups with different treatments of the experiment.

\begin{tabular}{|c|c|c|c|c|c|}
\hline \multirow{3}{*}{$\begin{array}{l}\text { Fish } \\
\text { groups }\end{array}$} & \multirow{3}{*}{$\begin{array}{l}\text { Fish exposed to contaminated } \\
\text { water with NO (112.5 ppm) }\end{array}$} & \multicolumn{4}{|c|}{ Without contaminated water with NO ppm } \\
\hline & & \multicolumn{2}{|c|}{ Fish fed food contained $\mathrm{CN}$} & \multirow{2}{*}{$\begin{array}{l}\text { Fish fed food contained } \\
\text { vit. E ( } 100 \mathrm{mg} / \mathrm{kg} \text { wet } \mathrm{wt})\end{array}$} & \multirow{2}{*}{$\begin{array}{l}\text { Fish exposed to } \\
\text { normal water }\end{array}$} \\
\hline & & CN1 (15 mg/100g) & $\mathrm{CN} 2(25 \mathrm{mg} / 100 \mathrm{~g})$ & & \\
\hline $\bar{I}$ & & & & & For the 4 weeks \\
\hline II & For the first 3 weeks & & & & \\
\hline III & & For the fourth week only & & & For the first 3 weeks \\
\hline IV & & & For the fourth week only & & For the first 3 weeks \\
\hline V & For the first 3 weeks & For the fourth week only & & & \\
\hline VI & For the first 3 weeks & & For the fourth week only & & \\
\hline VII & For the first 3 weeks & & & For the fourth week only & \\
\hline VIII & For the first 3 weeks & & & & For the fourth week only \\
\hline
\end{tabular}

$\mathrm{CN}=$ copper nicotinate, $\mathrm{NO}=$ neem oil, vit. $\mathrm{E}=$ vitamin $\mathrm{E}$.

At the end of the experiment, from each treatment, 5 fish were taken, sacrificed and dissected. The gills, liver, ovaries, posterior kidney and muscle (under the dorsal fin) were excised.

\section{Oxidative stress parameters activities}

For oxidative stress parameters activities analysis, parts of gill, liver, ovaries and muscle tissues were immediately kept at- $30{ }^{\circ} \mathrm{C}$ prior to analysis. At the beginning of each analysis, the samples were allowed to equilibrate to room temperature and samples of each tissue for each treatment group were pooled. Known weight of the each pooled tissue was homogenized in phosphate buffer $(\mathrm{pH}$ 7.4) using glass homogenizer. The homogenates were then centrifuged at 5,000 rpm for $15 \mathrm{~min}$ to separate the homogenate and all samples were aliquoted into Eppendorf tubes. All activities were measured spectrophotometrically by using 1203 UV, Shimadzu, Japan at $25^{\circ} \mathrm{C}$. Glutathione S-transferase (GST) activity was determined using 1-chloro-2, 4dinitrobenzene (CDNB) as substrate as described by (Habig et al., 1974). Catalase 
(CAT) activities of tissues were determined according to the method of (Aebi, 1974). The enzymatic decomposition of $\mathrm{H}_{2} \mathrm{O}_{2}$ was followed directly by the decrease in absorbance at $240 \mathrm{~nm}$. The difference in absorbance per unit time was used as a measure of CAT activity. Superoxide dismutase (SOD) activity was determined using the method of (Nishikimi et al., 1972).

\section{Histopathological examinations}

Parts of gills, liver and posterior kidney tissues were taken and preserved in $10 \%$ formalin for $24 \mathrm{~h}$, then washed with tap water and dehydrated by a series of upgraded ethanol solution $(70 \%, 80 \%, 90 \%, 95 \%$ and $100 \%)$, cleared in xylene, embedded in paraffin wax and sectioned at $5 \mu \mathrm{m}$ thick. Tissue sections were routinely processed and stained with Hematoxylin and Eosin (H\&E) (Humason, 1979) and then examined histopathologically by light microscopy according to (Roberts, 2012).

\section{Semiquantitative scoring for histopathology}

The histopathological lesions in the tissues were examined in the randomly selected five sections from each fish and 5 fish from each group per replicate. Histopathological alterations were assessed using a score ranging from - ve to +++ depending on the degree and extent of the alteration: $(-\mathrm{ve})$ none, $(+)$ mild occurrence, $(++)$ moderate occurrence, $(+++)$ severe occurrence (Bernet et al., 1999).

\section{Statistical analysis}

All statistical calculations (percentage ratio, \%) were estimated using the Microsoft Excel 2010 computer program.

\section{RESULTS}

\section{Oxidative stress parameters activities}

Table (2) shows a marked inhibition in GST, CAT and SOD antioxidants activities in studied organs of NO-treated fish than in the controls. GST activity was deleted in muscle $(13.35 \%)$, liver $(24.11 \%)$, ovary $(25.10 \%)$ and gills $(25.35 \%)$ in NO-treated fish.

Table 2: Effect of neem seed oil (NO), copper nicotinate (CN1), copper nicotinate (CN2), NO plus $\mathrm{CN} 1$, NO plus CN2, NO plus vitamin E (vit. E) and NO plus normal clean water (W) on glutathione S-transferase (GST) (U/g tissue), catalase (CAT) (U/g tissue) and superoxide dismutase (SOD) (U/g tissue) of gills, liver, ovaries and muscle in O. niloticus.

\begin{tabular}{|c|c|c|c|c|c|c|c|c|c|}
\hline & Tissue & Control & $\mathrm{NO}$ & CN1 & $\mathrm{CN} 2$ & $\mathrm{NO}+\mathrm{CN} 1$ & $\mathrm{NO}+\mathrm{CN} 2$ & $\mathrm{NO}+$ vit. E & $\mathrm{NO}+\mathrm{W}$ \\
\hline \multirow{4}{*}{$\underset{\mho}{\mathscr{W}}$} & Gills & 2.130 & 1.590 & 1.970 & 2.070 & 1.950 & 2.090 & 2.040 & 1.690 \\
\hline & liver & 12.980 & 9.850 & 11.240 & 13.140 & 12.640 & 16.740 & 14.280 & 12.640 \\
\hline & Ovary & 0.478 & 0.358 & 0.364 & 0.503 & 0.425 & 0.496 & 0.478 & 0.447 \\
\hline & Muscle & 0.427 & 0.370 & 0.424 & 0.554 & 0.346 & 0.567 & 1.056 & 0.432 \\
\hline \multirow{4}{*}{$\underset{\mho}{\longleftarrow}$} & Gills & 742.9 & 223.6 & 385.9 & 437.6 & 558.0 & 731.0 & 714 & 673.0 \\
\hline & liver & 1960.0 & 1362.0 & 1857.0 & 2847.0 & 3632.0 & 4864.0 & 4178 & 4106.0 \\
\hline & Ovary & 298.2 & 188.7 & 241.9 & 283.3 & 306.0 & 376.7 & 359 & 261.0 \\
\hline & Muscle & 776.5 & 218.3 & 463.9 & 511.7 & 632.5 & 808.0 & 747 & 385.9 \\
\hline \multirow{4}{*}{$\stackrel{\ominus}{\ominus}$} & Gills & 194 & 150 & 232.0 & 210 & 186 & 271 & 208 & 196 \\
\hline & liver & 189 & 131 & 208.0 & 291 & 242 & 302 & 292 & 177 \\
\hline & Ovary & 178 & 155 & 162.0 & 174 & 186 & 202 & 199 & 171 \\
\hline & Muscle & 230 & 112 & 216.2 & 225 & 209 & 244 & 231 & 166 \\
\hline
\end{tabular}

The highest activity of GST was in liver $(12.980 \mathrm{U} / \mathrm{g})$ in non-treated fish probably due to its characteristic powerful antioxidant system when comparing with other organs. GST was not higher over the controls in fish exposed to CN1 but it slightly increased in liver, ovary and muscle of fish exposed to CN2. CAT activity decreased in liver $(30.51 \%)$, ovary $(36.72 \%)$, gills $(69.90 \%)$ and muscle $(71.89 \%)$ in 
NO-treated fish. CAT was not higher over the controls in fish exposed to CN1 but it increased in liver of fish exposed to CN2. SOD activity dropped in ovary (12.92\%), gills $(22.68 \%)$, liver $(30.69 \%)$ and muscle $(51.30 \%)$ in NO-treated fish. SOD activity was not higher over the controls in ovary and muscle but it increased in gills and liver of fish exposed to both CN1 and CN2.

Among the therapeutic treatment groups of $\mathrm{CN} 1, \mathrm{CN} 2$, vitamin $\mathrm{E}$ and normal clean water on NO-treated fish, it showed that $\mathrm{CN} 2$ and vitamin $\mathrm{E}$ were the most restoring and enhancing effect against neem seed oil toxicity in gills, liver, ovary and muscle. The result shows that $\mathrm{CN} 1(15 \mathrm{mg} / 100 \mathrm{~g}$ wet food) has failed to normalize activities of GST in all studied tissues and CAT in gills and muscle of NO-treated fish. However, the CN2 (25 mg/100 g wet food) restored and enhanced the activities of GST and CAT in liver, ovary and muscle of NO-treated fish, while gills showed some recovery. Vitamin E, which used in this experiment as standard antioxidant, restored and enhanced the activities of GST in liver, ovary and muscle and CAT in liver and ovary of NO-treated fish, while GST in gills and CAT in gills and muscle showed some recovery. In addition, the result shows that CN1 (15 mg/100 g wet food) has failed to normalize activities of SOD in gills and muscle of NO-treated fish. The $\mathrm{CN} 2(25 \mathrm{mg} / 100 \mathrm{~g}$ wet food) and Vitamin E restored and enhanced the activities of SOD in all studied tissues.

\section{Histopathological findings}

The histological alterations found in the organs of $O$. niloticus fish in different experimental groups are detailed in Table (3) and figures (1-3). In the present study, the histopathological examination showed marked deterioration in case of NO-treated fish organs than in the controls, on the other hand mild deteriorations than in the controls were observed in NO plus CN2 as well as NO plus vitamin E, while in the other groups the histopthological alterations were moderate in comparison. At the end of recovery period ( 1 week in clean water), an improvement in the oxidative stress parameters and histopathological changes could be observed. However, the fish did not show complete recovery.

\section{DISCUSSION}

Many studies have indicated that extracts of neem plant may possess significant antioxidant properties that can boost the blood antioxidant status (Arivazhagan et al., 2004) and significantly protect the animals against oxidative stress (Gupta et al., 2004). In fish, antioxidant enzymes have been shown to be either induced or inhibited by pollutants, depending on the dose, the species and/or the route of exposure (Sanchez et al., 2005).

Glutathione S-transferase (GST) plays a key role in protecting tissues from oxidative stress (Al-Salahy, 2011 and Zhang et al., 2004). The present study have shown that NO decreased GST activity in all studied organs. The inhibition of GST activity in organs of NO-treated $O$. niloticus fish may reflect impairment in the detoxifying capacity of the fish at levels above the used $\mathrm{LC}_{50}$ (Winkaler et al., 2007). Similarly, Farombi et al., (2007) found a significant decrease in GST activity in the gills of $C$. gariepinus in response to pollution with heavy metals. GST activity was inhibited in gills, liver, intestine and muscle of $J$. multidentata fish exposed to endosulfan (Ballesteros et al., 2009). Al-Salahy (2011) observed a significant decrease in GST activity in organs of $C$. gariepinus fish, exposed to mercuric chloride. 
Table (3): Histolopathological alterations found in the liver (heptopancreas), posterior kidney and gills of $O$. niloticus fish in different experimental groups and their respective degrees of damage to the tissue.

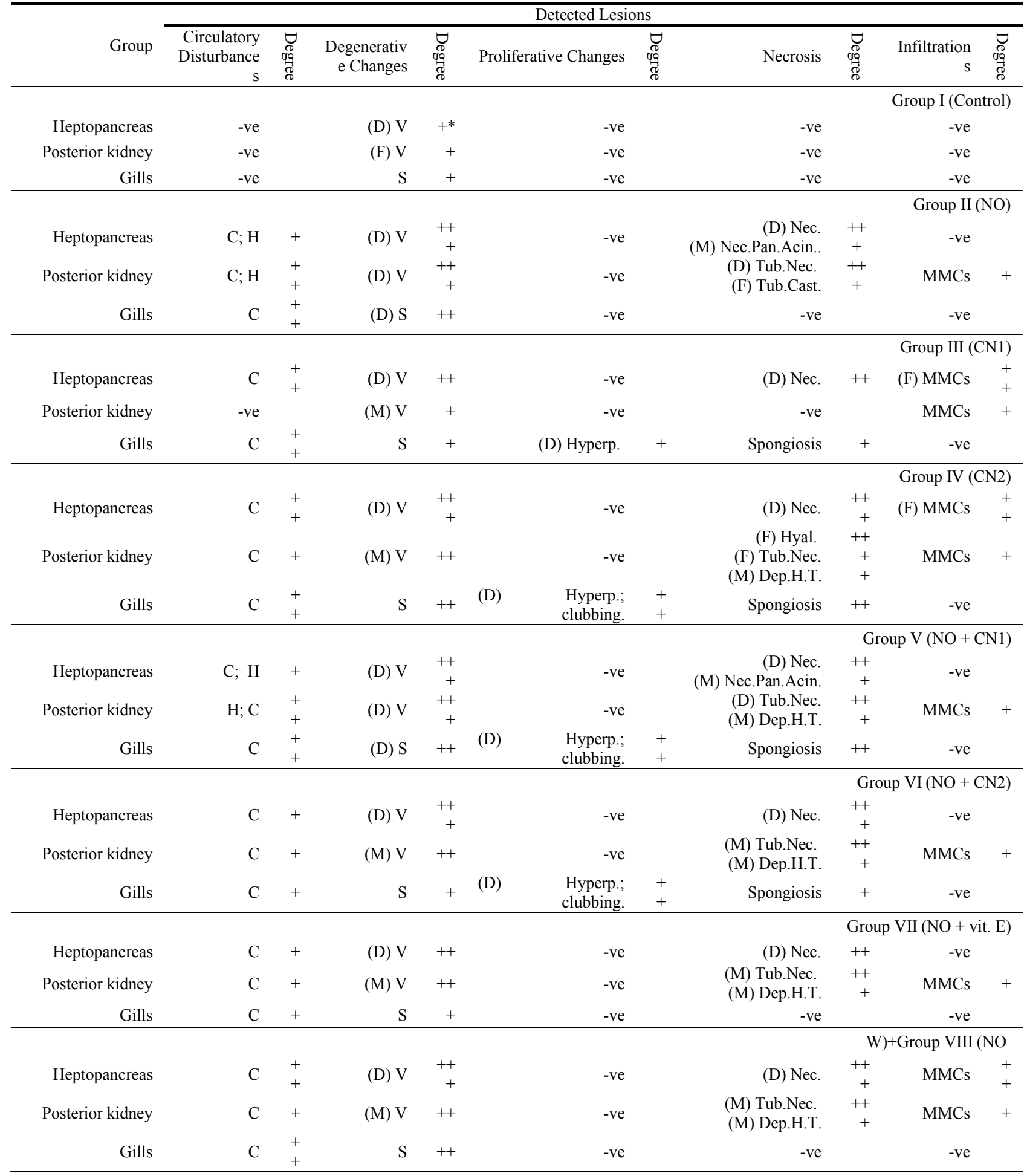

*Score value: $-\mathrm{ve}=$ none, $+=$ mild, $++=$ moderate, $+++=$ severe; (D) Diffuse, (M) Multifocal, (F) Focal, C Congestion. [H] Heamorrhages, [S] Separation in-between the epithelial cell lining of the secondary gill lamellae and the underlying capillary bed, [V] vacuolar degeneration, [N] necrosis, [MMCs] activation of melanomacrophage centers, [Tub.Nec.] tubular necrosis, [Dep.H.T.] Depletion of heamopoeitic tissue, [Hyperp.] hyperplasia of the epithelial lining at the base of the secondary gill lamellae, [Spongiosis] necrotic changes in-between the proliferated malpighian cells, [Hyal.] hyaline droplet deposition, [Tub.Cast.] tubular casts, [Pan.Acin.] pancreatic acinai. 
On the other hand, conversely, the present results disagree with those of (Winkaler et al., 2007) who reported activation in hepatic GST activity of $P$. lineatus fish, following the exposure to $5.0 \mathrm{gL}^{-1}$ of neem leaf extract. The inhibition of GST could be explained by different hypothesis. First biotransformation steps by cytochrome P450 enzymes may produce a cocktail of different metabolites, competing with GST substrates for the active sites on the GST enzyme. Second lower levels caused by a decrease in the synthesis of GST proteins at molecular levels (Ballesteros et al., 2009).

Catalase (CAT) counteracts the toxicity of reactive oxygen species (ROS) and facilitates the removal of hydrogen peroxide $\left(\mathrm{H}_{2} \mathrm{O}_{2}\right)$ which is metabolized to molecular oxygen $\left(\mathrm{O}_{2}\right)$ and water (Van der Oost et al., 2003 and Zhang et al., 2004). The present study showed obvious drop of CAT activity in gills, liver, ovary and muscle, with highest decrease in gills and muscle in fish treated with NO. This drop may attribute to the excessive production of $\mathrm{H}_{2} \mathrm{O}_{2}$ in response to toxicity of NO, which probably leading to the consumption of CAT enzyme in these organs. In addition, the decreased CAT activity may be due to the flux of superoxide radicals, due to the oxidative stress caused by pollutants exposure, which have been shown to inhibit CAT activity (Andric et al., 2006). Our present results are in good agreement with those found by (Sayeed et al., 2003) reporting that, the exposure of C. punctatus to Deltamethrin produced a significant decrease in CAT activity in the liver, kidney and gill tissues. Also (Winkaler et al., 2007) demonstrated significant reduction in hepatic CAT activity of $P$. lineatus fish, following the exposure to different concentrations of neem leaf extract, which is likely to affect the capacity of liver cells to defend themselves and respond to contaminant-induced oxidative stress. The activity of CAT was significantly decreased in the liver of $J$. multidentata exposed to endosulfan (Ballesteros et al., 2009). In addition, Al-Salahy (2011) observed a significant decrease in CAT activity in organs of $C$. gariepinus fish, exposed to mercuric chloride. Xing et al.(2012) showed that the activity of CAT was reduced in the brain and kidney of common carp after exposure to atrazine and chlorpyrifos pesticides.

Superoxide dismutase (SOD) catalyzes the transformation of superoxide radicals, as soon as liberated, to $\mathrm{H}_{2} \mathrm{O}_{2}$ and $\mathrm{O}_{2}$, and is the first enzyme to deal with oxyradicals ( Zhang et al., 2004). In this study, the decreasing effect of NO on SOD activity in gills, liver, ovary and muscle accompanied with significant decrease in CAT activity may reflect excessive production of ROS in response to NO dose in the fish. CAT and SOD enzymes have related functions. SOD catalyzes the dismutation of the superoxide anion radical to $\mathrm{H}_{2} \mathrm{O}$ and $\mathrm{H}_{2} \mathrm{O}_{2}$, which is detoxified by CAT activities (Özkan et al., 2012). Similarly, to our study, Thomaz et al. (2009) reported that SOD activity was decreased in liver of $O$. niloticus exposed to the insecticide trichlorfon. Al-Salahy (2011) observed a significant decrease in SOD activity in organs of $C$. gariepinus fish, exposed to mercuric chloride. SOD activity was reduced in the brain and kidney of common carp after exposure to atrazine and chlorpyrifos ( Xing et al., 2012). In addition, SOD activity was decreased in liver of $O$. niloticus fish after exposure to chlorpyrifos concentrations (Özkan et al., 2012).

Many studies were conducted to test many antioxidants to protect fish against different pollutants by either dissolving it in water or in food supplementation (AlSalahy, 2011). Our present study showed that all oxidative perturbations appeared in gills, liver, ovary and muscle were either abolished or attenuated in fish treated with NO for 21 days followed by treatment with $\mathrm{CN}$ and vitamin $\mathrm{E}$ for 7 days. The increased levels of studied antioxidants activities in the treatment groups might have 
occurred due to trigger of antioxidants by $\mathrm{CN}$ and vitamin $\mathrm{E}$ and resulted in lower oxidative stress in the treated groups. This result may be attributed to scavenging free radical effect of $\mathrm{CN}$ and vitamin $\mathrm{E}$, increasing endogenous antioxidants, healing of gill lamellae through enhancing angiogenesis, allowing to normal osmoregulation and respiration and consequently prevent tissue anoxia. This interpretation is based on the findings of (Al-Salahy, 2011). Sorenson, 1989 and Salama et al., 2007). The efficacy of $\mathrm{CN}$ to counteract oxidative damaging effect of $\mathrm{NO}$ observed in the present work was near to that of vitamin $\mathrm{E}$ that used in the same circumstance. Similarly, AlSalahy,( 2011) found that the addition of $C N$ and vitamin $E$ to diet decreased the oxidative stress in organs of $C$. gariepinus exposed to mercuric chloride. Cengiz et al.(2012) demonstrated that administration of vitamin E decreases the peroxidation of unsaturated fatty acids and protects the cell membranes in gill and liver tissues of $O$. niloticus exposed to deltamethrin. The addition of vitamin $\mathrm{E}$ to diet decreased the frequencies of micronucleus in peripheral erythrocytes of $O$. niloticus exposed to deltamethrin (Kan et al., 2012).

Histopathological investigations can be used as sensitive biomonitoring tools for health in toxicity studies to detect direct effects of chemical compounds within target organs of fish in laboratory experiments, particularly for sub lethal and chronic effects (Authman et al., 2012; Bernet et al., 1999 and Authman et al., 2013).

Fish gills are multifunctional organs involved in respiration, ion transport, acidbase balance and excretion of nitrogenous wastes in fish. They represent the greatest area in close contact with the external environment, and particularly sensitive to changes in the quality of the water, so they are considered the primary target of the contaminants (Heath, 1995 and Fernandes and Mazon, 2003). In this study, the gills showed marked signs of degeneration and hyperplasia than in the control group; this may be attributed to the contact irritation of neem oil to the gills leading to epithelial necrosis. These alterations were minimal in case of NO plus vitamin E. Gill hyperplasia has been suggested as a defensive mechanism resulting into a decrease in the respiratory surface and increase the distance between external environment and the blood, thus forming a barrier to the entrance of contaminants (Mallat, 1985 and Cengiz, 2006). Camargo and Martinez (2007) have opined that as a consequence of the increased distance between water and blood caused by epithelial lifting the oxygen uptake is impaired. The lesions observed in the present study may result in decreased oxygen-uptake capacity of the gill making the fish exposed to neem less able to get adequate oxygen for its total metabolic activity. In this case a subsequent internal hypoxia would be expected to occur (Winkaler et al., 2007). Alterations in NOexposed $O$. niloticus gills were similar to that noticed in gills of $P$. lineatus, exposed to neem leaf extract by (Winkaler et al., 2007) which include hyperplasia, hpithelial lifting, fusion, lamellar aneurism and rupture of the lamellar epithelium. The common gill alterations observed in $H$. fossilis fish exposed to purified neem extract azadirachtin were over-secretion of mucous, hyperplasia and fusion of gill lamellae, epithelial uplifting and necrosis of gill epithelial cells (Kumar et al., 2010). Epithelial hypertrophy, lifting of epithelia, hypertrophy of mucus cells, mucus accumulation in seconder lamella, and fusion of secondary lamellae were noted in the gills of $O$. niloticus exposed to deltamethrin pesticide ( Kan et al., 2012).

The liver is the primary organ for metabolism, detoxification of xenobiotics and excretion of harmful substances (Van der Oost et al., 2003). It is also one of the organs most affected by contaminants in the water (Camargo and Martinez, 2007). In the present study, hepatocytic vacoulation was noticed in all groups in variable degrees of intensity even in the control group with minimal pathological alterations in 
case of NO plus vitamin E then with NO plus CN2, respectively. Vacoulation may be due to glycogen storage in hepatocytes or due to hydropic degeneration due to chemical contamination. These histopathologies are consistent with those reported by other workers. Liver of $C$. idellus exposed to fenvalerate expressed degeneration of hepatocytes, necrosis and disappearance of hepatocyte wall (Tilak et al., 2001). Hyperplasia, disintegration of hepatic mass, focal coagulative and necrosis were seen in liver of L. rohita exposed to cypermethrin (Sarkar et al., 2005). Moderate fatty vacuolation of the hepatocytes in monosex Nile tilapia exposed to deltamethrin was observed by (El-Sayed and Saad, 2008). Hypertrophy of hepatocytes, vacuolar degeneration, fatty degeneration, nuclear pycnosis, focal necrosis and cells which have double nucleus were observed in the liver of $O$. niloticus exposed to deltamethrin (Kan et al., 2012).

The kidney is a vital organ of body and proper kidney function is to maintain the homeostasis. Fish kidney receives the major part of the blood coming from the gill and is one of the first organs to be affected by contaminants in the water (Mekkawy et al., 2013). In the present study, it is apparent that in all fish groups treated with neem oil, the posterior kidney was severely affected by degenerative and necrotic changes than the control group, with minimal pathological alterations in case of NO plus vitamin $\mathrm{E}$ then with $\mathrm{NO}$ plus $\mathrm{CN} 2$, respectively. Usually, the alterations in the posterior kidney of fish exposed to water contamination correspond to changes in tubules, such as granular and hyaline degeneration and changes in the corpuscle, such as dilatation of capillaries in the glomerulus and reduction of Bowman's space (Takashima and Hibiya, 1995). Many of these alterations are among the ones observed in the posterior kidney of $O$. niloticus exposed to neem seed oil. The present results are in agreement with those observed in $P$. lineatus exposed to neem leaf extract (Winkaler et al.,2007) which include glomerular expansion, resulting in reduction of Bowman's space, cytoplasmic vacuolation, granular degeneration and narrowing of tubular lumen. In addition, kidney alterations were observed in L. rohita exposed to hexachlorocyclohexane (Das and Mukherjee, 2000). Velmurugan et al. (2007) recorded sever changes in the kidney tissues of $C$. mrigala exposed to lambdacyhalothrin. While, Benli et al (2008) reported displayed glomerulonephritis and hyperemia in the kidney of $O$. niloticus exposed to ammonia. The kidney of common carp exposed to atrazine and chlorpyrifos displayed different degrees of cloudy swelling of epithelial cells of renal tubules, necrosis in the tubular epithelium, contraction of the glomerulus and expansion of Bowman's space( Xing et al., 2012).

All treated groups except control showed marked activation of melano macrophage centers (MMCs) with exaggerated activation in case of neem oil treated groups, this may be indicative to exposure to water chemical pollutant (Agius and Roberts, 2003).

In comparison with the obtained results of the oxidative stress parameters activities, with the histopathological picture, it can be concluded that the pathological picture is exponentially related to the severity of the chemical oxidative stress, with minimal total pathology in case of using vitamin $\mathrm{E}$ then $\mathrm{CN} 2$, respectively as antioxidants.

\section{CONCLUSION}

The current study indicated that NO had adverse effects on $O$. niloticus fish probably due to its enhancing effect on ROS production and inducing histopathological alterations in fish organs. On the other hand, it was observed that the 
addition of $\mathrm{CN}$ and vitamin $\mathrm{E}$ in fish diets repaired these effects and improved the histopathological changes induced by NO in some degree. It can be concluded that $\mathrm{CN}$ and vitamin $\mathrm{E}$, as antioxidants, have protective effects against $\mathrm{NO}$ adverse effects by inactivating (scavenging) free radicals generated following exposure and supplementation of $\mathrm{CN}$ and vitamin $\mathrm{E}$ might be beneficial for fish populations exposed to NO. Finally, precautions must be taken into account when botanicals are being used in fish production facilities, and extensive investigations should be established for the suitable methods of application to be fully explored in future. Also, Environmental managers and government authorities concerned with water quality standards should develop water quality criteria to regulate the use of these plant extracts in the aquatic environment.

\section{REFERENCES}

Abbas, H.H.H.; Hammada, M. M. and Miller, J. D. (2007). Vitamin C and cadmium toxicity in fish Oreochromis niloticus. Online J. Vet. Rese., 11(1): 54-74.

Aebi, H. (1974). Catalase. In: Bergmayer, H.U. (ed.), Methods of enzymatic analysis. Academic Press, New York, pp. 671-684.

Agius, C. and Roberts, R. J. (2003). Melano-macrophage centres and their role in fish pathology. J. Fish Diseases, 26(9): 499-509.

Ahmad, I.; Hamid, T.; Fatima, M.; Chand, H.S.; Jain, S.K.; Athar, M. and Raisuddin, S. (2000). Induction of hepatic antioxidants in freshwater catfish (Channa punctatus Bloch) is a biomarker of paper mill effluent exposure. Biochimica et Biophysica Acta, 1523(1): 37- 48.

Al-Salahy, M.B. (2011). Physiological studies on the effect of copper nicotinate $(\mathrm{Cu}-$ $\mathrm{N}$ complex) on the fish, Clarias gariepinus, exposed to mercuric chloride. Fish Physiol. Biochem., 37(3): 373-385.

Ansari, B. A. and Sharma, D. K. (2009). Toxic effect of synthetic pyrethroid Deltamethrin and Neem Based formulation Achook on Zebrafish, Danio rerio. Trends in Biosci., 2(2): 18-20.

Arivazhagan, S.; Velmurugan, B.; Bhuvaneswari V. and Nagini, S. (2004). Effects of aqueous extracts of garlic (Allium sativum) and neem (Azadirachta indica) leaf on hepatic and blood oxidant-antioxidant status during experimental gastric carcinogenesis. J. Med. Food, 7(3): 334-339.

Authman, M. M. N.; Abbas, W.T. and Gaafar, A.Y. (2012). Metals concentrations in Nile tilapia Oreochromis niloticus (Linnaeus, 1758) from illegal fish farm in AlMinufiya Province, Egypt, and their effects on some tissues structures. Ecotoxicol. and Environm. Safety, 84: 163-172.

Authman, M. M. N.; Abbas, W. T.; Abomourad, I. M. K. and Kenawy, A.M. (2013). Effects of illegal cyanide fishing on vitellogenin in the freshwater African catfish, Clarias gariepinus (Burchell, 1822). Ecotoxicol. Environ. Safety, 91: 61-70.

Ballesteros, M.L.; Wunderlin D. A. and Bistoni, M. A. (2009). Oxidative stress responses in different organs of Jenynsia multidentata exposed to endosulfan. Ecotoxicol. Environ., Safety, 72(1): 199-205.

Bebe, F. N. and Panemangalore, M. (2003). Exposure to low doses of endosulfan and chlorpyrifos modifies endogenous antioxidants in tissues of rats. J. Environ. Sci. Health B, 38(3): 349-363. 
Benli, A. C. K.; Köksal, G. and Özkul, A. (2008). Sublethal ammonia exposure of Nile tilapia (Oreochromis niloticus L.): Effects on gill, liver and kidney histology. Chemosphere, 72(9): 1355-1358.

Bernet, D.; Schmidt, H.; Meier, W.; Burkhardt-Holm, P. and Wahli, T. (1999). Histopathology in fish: proposal for a protocol to assess aquatic pollution. J. Fish Diseases, 22(1): 25-34.

Biswas, K.; Chattopadhyay, I.; Banerjee, R. K. and Bandyopadhyay, U. (2002). Biological activities and medicinal properties of neem (Azadirachta indica). Current Sci., 82(11): 1336-1345.

Camargo, M. M. P. and Martinez, C. B. R. (2007). Histopathology of gills, kidney and liver of a neotropical fish caged in an urban stream. Neotrop. Ichthyol., 5(3): 327-336.

Cengiz, E. I. (2006). Gill and kidney histopathology in the freshwater fish Cyprinus carpio after acute exposure to deltamethrin. Environ. Toxicol. Pharmacol., 22(2): 200-204.

Cengiz, E. I.; Kan, Y.; Kizmaz, V.; Başhan, M. and Yanar, M. (2012). The protective role of vitamin $\mathrm{E}$ on the fatty acid composition of phospholipid structure in gill and liver tissues of Oreochromis niloticus exposed to deltamethrin. Ecotoxicol. Environ. Safety, 80: 381-385.

Craig, P.M.; Wood, C. M. and McClelland, G. B. (2007). Oxidative stress response and gene expression with, acute copper exposure in zebrafish (Danio rerio). Amer. J. of Physiol.- Regulat. Integrat. and Comp. Physiol., 293: R1882R1892.

Das, B. K. and Mukherjee, S. C. (2000). A histopathological study of carp (Labeo rohita) exposed to hexachlorocyclohexane. Veterinarski Arhiv, 70(4): 169-180.

Dunkel, F. V. and Richards, D. C. (1998). Effect of an azadirachtin formulation on six nontarget aquatic macroinvertebrates. Environ. Entomol., 27(3): 667-674.

El-Sayed, Y. S. and Saad, T. T. (2008). Subacute intoxication of a deltamethrin-based preparation (Butox ${ }^{\circledR} 5 \%$ EC) in monosex Nile Tilapia, Oreochromis niloticus L. Basic \& Clinical Pharmacology \& Toxicology, 102(3): 293-299.

Farombi, E. O.; Adelowo, O. A. and Ajimoko, Y. R. (2007). Biomarkers of oxidative stress and heavy metal levels as indicators of environmental pollution in African cat fish (Clarias gariepinus) from Nigeria Ogun River. International J. Environ. Rese. and Public Health, 4(2): 158-165.

Fernandes, M. N. and Mazon, A. D. F. (2003). Environmental pollution and fish gill morphology. In: Val, A.L. and B.G. Kapoor (Eds.), Fish Adaptations. Enfield, NH: Scientific Publishers Inc., pp. 203-231.

Garcia-Santos, S., A. Fontainhas-Fernandes and J.M. Wilson, 2006. Cadmium tolerance in the Nile tilapia (Oreochromis niloticus) following acute exposure: assessment of some ionoregulatory parameters. Environmental Toxicology, 21(1): 33-46.

Goher, M.A.S., 1987. Crystal structure of a ploymeric 2:1 complex of nicotinic acid with copper (I) chloride. Inorganica Chimica Acta, 127(1): L13-L16.

Gupta, S., M. Kataria, P.K. Gupta, S. Murganandan and R.C. Yashroy, 2004. Protective role of extracts of neem seeds in diabetes caused by streptozotocin in rats. J. Ethnopharmacol., 90(2-3): 185-189.

Habig, W.H., M.J. Pabst and W.B. Jakoby, 1974. Glutathione-S-transferases. The first enzymatic step in mercapturic acid formation. J. Biol. Chem., 249(22): 7130-7139. 
Hassanein, H.M.A. and H.A. Okail, 2008. Toxicity determination and hypoglycaemic effect of neem biopesticide on the grass carp "Ctenopharyngodon idella". Egyptian Academic J. Biol. Sci., 1(2): 37-49.

Heath, A.G., 1995. Water Pollution and Fish Physiology, $2^{\text {nd }}$ ed. CRC Press Inc., Lewis Publishers, Boca Raton, 384pp.

Hu, G.F., 1998. Copper stimulates proliferation of human endothelial cells under culture. Journal of Cellular Biochemistry, 69(3): 326-335.

Humason, G.L., 1979. Animal Tissue Techniques, $4^{\text {th }}$ ed. W.H. Freeman and company, San Francisco, CA, USA, 661pp.

Jacobson, M., 1995. Toxicity of neem to vertebrates and side effects on beneficial and other ecologically important non-target organisms: toxicity to vertebrates. In: Schmutterer, H. (Ed.), The Neem Tree Azadirachta indica A. Juss and other meliaceous plants: sources of unique natural products for integrated pest management, medicine, industry and other purposes. Weinheim, New York, pp. 484-495.

Kan, Y., E.I. Cengiz, P. Ugurlu and M. Yanar, 2012. The protective role of vitamin E on gill and liver tissue histopathology and micronucleus frequencies in peripheral erythrocytes of Oreochromis niloticus exposed to deltamethrin. Enviro. Toxicol. Pharmacol., 34(2): 170-179.

Kumar, A., M.R. Prasad, K. Srivastava, S. Tripathi and A.K. Srivastav, 2010. Branchial histopathological study of Catfish Heteropneustes fossilis following exposure to purified neem extract, Azadirachtin. World J. Zool., 5(4): 239-243.

Mallat, J., 1985. Fish gill structural changes induced by toxicants and other irritants: a statistical review. Canad. J. Fish. Aquat. Sci., 42(4): 630-648.

Martinez, S.S., 2002. O nim Azadirachta indica: natureza, usos múltiplose, produção. Londrina: Instituto Agronômico do Paraná (IAPAR), 142pp.

Mekkawy, I.A.A., U.M. Mahmoud, E.T. Wassif and M. Naguib, 2013. Effects of cadmium on some histopathological and histochemical characteristics of the kidney and gills tissues of Oreochromis niloticus (Linnaeus, 1758) dietary supplemented with tomato paste and vitamin E. J. Fish. Aquat. Sci., 8(5): 553-580.

Méndez, J.A., M.R. Aguilar, G.A. Abraham, B. Vázquez, M. Dalby, L. Di Silvio and J. San Roman, 2002. New acrylic bone cements conjugated to vitamin E: curing parameters, properties, and biocompatibility. J. Biomed. Mat. Rese., 62(2): 299-307.

Mousa, M.A.A., A.M.M. El-Ashram and M. Hamed, 2008. Effect of neem leaf extract on freshwater fishes and zooplankton community. Proceedings of the $8^{\text {th }}$ International Symposium on Tilapia in Aquaculture, Central Laboratory for Aquacult. Rese., October 12-14, 2008, Cairo, Egypt, pp. 307-318.

Nishikimi, M., N.A. Roa and K. Yagi, 1972: The occurrence of superoxide anion in the reaction of reduced phenazine methosulfate and molecular oxygen. Biochemical and Biophysical Research Communications, 46(2): 849-854.

Omoregie, E. and M.A. Okpanachi, 1992. Growth of Tilapia zilli exposed to sublethal concentrations of crude extracts of Azadirachta indica. Acta Hydrobiolog., 34(3): 281-286.

Omoregie, E. and M.A. Okpanachi, 1997. Acute toxicity of water extracts of bark of the neem plant, Azadirachta indica (Lodd) to the cichlid, Tilapia zilli (Gervais). Acta Hydrobiolog., 39(1/2): 47-51.

Oti, E.E. and U.H. Ukpabi, 2005. Acute toxicity of water extracts of barks of yellow oleander, Thevetia peruviana (Persoon), and neem plant, Azadirachta indica 
(Lodd) to Mormyrids, Hyperopisus bebe occidentalis (Gunther). J. Appl. Aquacult., 16(3-4): 183-190.

Özkan, F., S.G. Gündüz, M. Berköz, A.Ö. Hunt and S. Yalın, 2012. The protective role of ascorbic acid (vitamin $\mathrm{C}$ ) against chlorpyrifos-induced oxidative stress in Oreochromis niloticus. Fish Physiol. Biochemi., 38(3): 635-643.

Pereira, L., M.N. Fernandes and C.B.R. Martinez, (2013). Hematological and biochemical alterations in the fish Prochilodus lineatus caused by the herbicide clomazone. Environ. Toxicol. Pharmacol., 36(1): 1-8.

Roberts, R.J., 2012. Fish Pathology, $4^{\text {th }}$ ed., Blackwell Publishing Ltd., A John Wiley $\&$ Sons, Ltd., Publication, The Atrium, Southern Gate, Chichester, West Sussex, PO19 8SQ, UK, 462pp.

Salama, R.H.M., A.Y.A. Nassar, A.A.M. Nafady and H.H.T. Mohamed, (2007). A novel therapeutic drug (copper nicotinic acid complex) for non-alcoholic fatty liver. Liver International, 27(4): 454-464.

Sanchez, W., O. Palluel, L. Meunier, M. Coquery, J.M. Porcher and S. Aït-Aïssa, (2005). Copper-induced oxidative stress in three-spined stickleback: relationship with hepatic metal levels. Environ. Toxicol. Pharmacol., 19(1): 177-183.

Sarkar, B., A. Chatterjee, S. Adhikari and S. Ayyappan, (2005). Carbofuran-and cypermethrin-induced histopathological alterations in the liver of Labeo rohita (Hamilton) and its recovery. J. Appl. Ichthyol., 21(2): 131-135.

Sayeed, I., S. Parvez, S. Pandey, B. Bin-Hafeez, R. Haque and S. Raisuddin, (2003). Oxidative stress biomarkers of exposure to deltamethrin in freshwater fish, Channa punctatus Bloch. Ecotoxicol. Environ. Safety, 56(2): 295-301.

Sorenson, J.R.J., 1989. Copper complexes offer a physiological approach to treatment of chronic diseases. Progress in Medicinal Chemistry, 26: 437-568.

Stanic, B., N. Andric, S. Zoric, G. Grubor-Lajsic and R. Kovacevic, (2006). Assessing pollution in the Danube River near Novi Sad (Serbia) using several biomarkers in sterlet (Acipenser ruthenus L.). Ecotoxicol. Environ. Safety, 65(3): 395-402.

Takashima, F. and T. Hibiya, (1995). An Atlas of Fish Histology, Normal and Pathological Features, $2^{\text {nd }}$ ed., Gustav Fischer Verlag, Kodansha, 195pp.

Talpur, A.D. and M. Ikhwanuddin, (2013). Azadirachta indica (neem) leaf dietary effects on the immunity response and disease resistance of Asian seabass, Lates calcarifer challenged with Vibrio harveyi. Fish \& Shellfish Immunol., 34(1): 254-264.

Thomaz, J.M., N.D. Martins, D.A. Monteiro, F.T. Rantin and A.L. Kalinin, (2009). Cardio-respiratory function and oxidative stress biomarkers in Nile tilapia exposed to the organophosphate insecticide trichlorfon $\left(\mathrm{NEGUVON}^{\circledR}\right)$. Ecotoxicol. Environ. Safety, 72(5): 1413-1424.

Tilak, K.S., K. Veeraiah, T.A. Susan and K. Yacobu, (2001). Toxicity and residue studies of fenvalerate to some selected freshwater fishes. J. Environ. Biolo./ Academy of Environ. Biolo., India, 22(3): 177-180.

Valavanidis, A., T. Vlahogianni, M. Dassenakis and M. Scoullos, 2006. Molecular biomarkers of oxidative stress in aquatic organisms in relation to toxic environmental pollutants. Ecotoxicol. Environ. Safety, 64(2): 178-189.

Van der Oost, R., J. Beyer and N.P.E. Vermeulen, (2003). Fish bioaccumulation and biomarkers in environmental risk assessment: a review. Environ. Toxicol. Pharmacol., 13(2): 57-149.

Velmurugan, B., M. Selvanayagam, E.I. Cengiz and E. Unlu, (2007). Histopathology of lambda-cyhalothrin on tissues (gill, kidney, liver and intestine) of Cirrhinus mrigala. Environ. Environ. Toxicol. Pharmacol., 24(3): 286-291. 
Winkaler, E.U., T.R.M. Santos, J.G. Machado-Neto and C.B.R. Martinez, (2007). Acute lethal and sublethal effects of neem leaf extract on the neotropical freshwater fish Prochilodus lineatus. Comp. Biochem. Physiol. C, 145(2): 236244.

Xing, H., S. Li, Z. Wang, X. Gao, S. Xu and X. Wang, (2012). Histopathological changes and antioxidant response in brain and kidney of common carp exposed to atrazine and chlorpyrifos. Chemosph., 88(4): 377-383.

Zhang, J., H. Shen, X. Wang, J. Wu and Y. Xue, (2004). Effects of chronic exposure of 2,4-dichlorophenol on the antioxidant system in liver of freshwater fish Carassius auratus. Chemosph., 55(2): 167-174. 


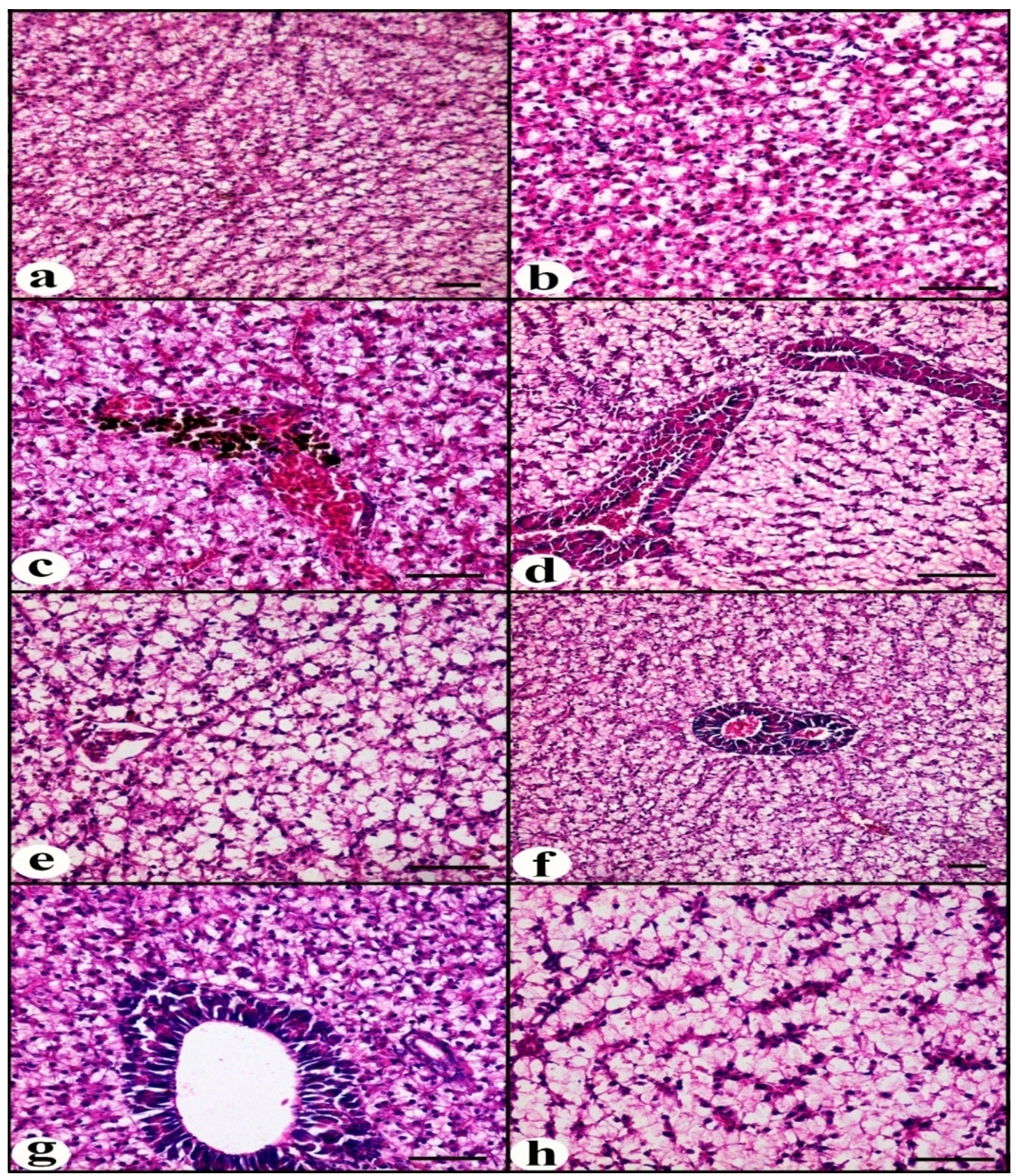

Fig. 1: Photomicrographs of Transverse sections of hepatopancreas of O. niloticus (H\&E x 100) (a) Group I showing diffuse small intracytoplasmic vacuoles. (b) - Group II showing diffuse vacuolar degeneration and hepatocytic necrosis. (c) - Group III showing congestion of main blood vessels and sinusoidal spaces with diffuse vacuolar degeneration associated with focal activation of melanomacrophage centers near main blood vessels. (d) - Group IV showing congestion of main blood vessels and sinusoidal spaces and diffuse vacuolar degeneration and hepatocytic necrosis. (e) - Group V showing congestion of main blood vessels, diffuse vacuolar degeneration and diffuse hepatocytic necrosis. (f) - Group VI showing congestion of main blood vessels and sinusoidal spaces and diffuse vacuolar degeneration. (g) - Group VII showing congestion of main blood vessels and sinusoidal spaces and diffuse vacuolar degeneration. (h) Group VIII showing congestion of sinusoidal spaces and diffuse vacuolar degeneration and hepatocytic necrosis. 


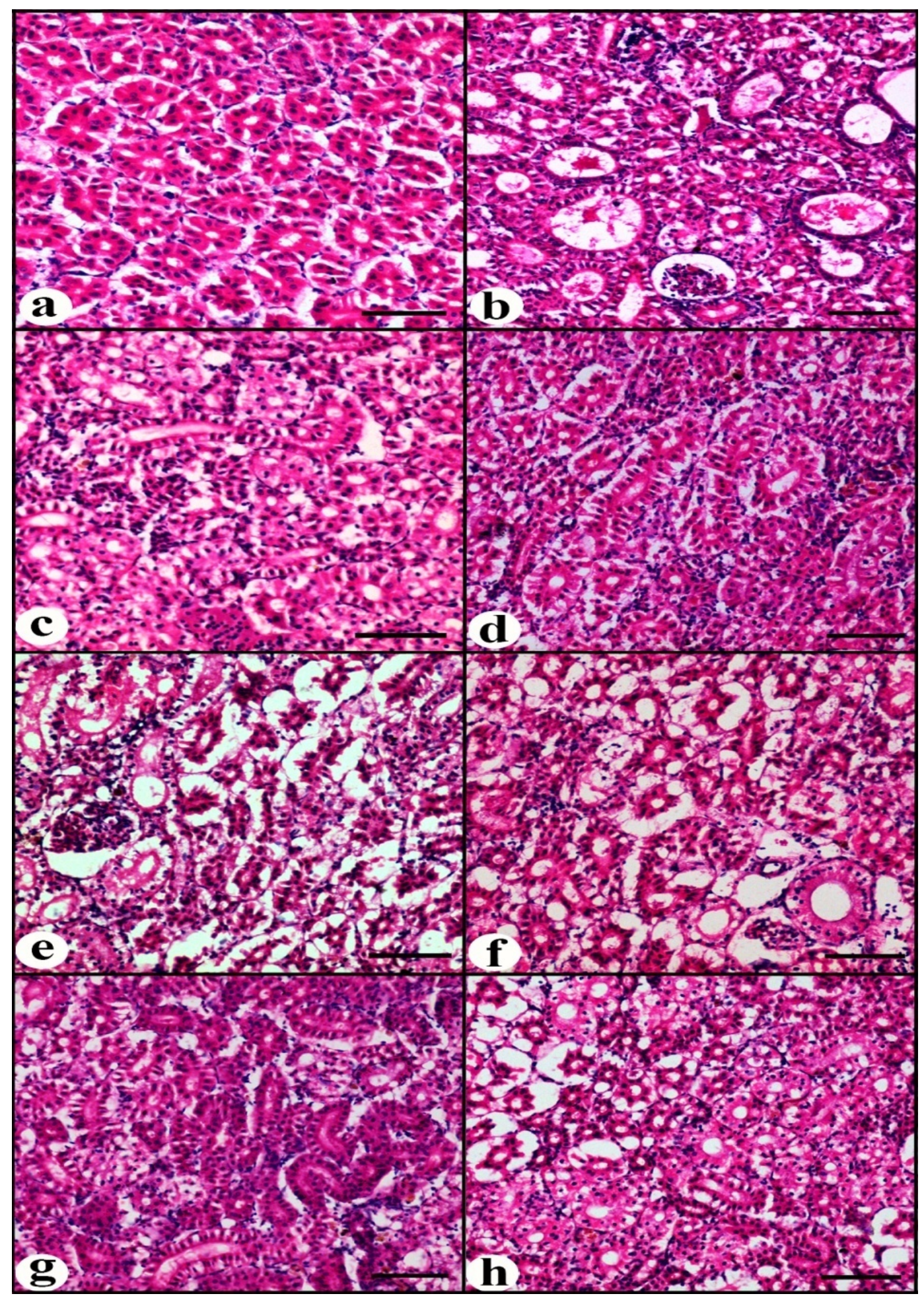

Fig. 2: Photomicrographs of Transverse sections of hepatopancreas of posterior kidney O. niloticus (H\&E x 100) (a) - Group I (the control group) showing some separation of tubular epithelium from basement membranes. (b) - Group II showing vacuolation of tubular epithelial cells and tubular cast formation. (c) - Group III vacuolation of tubular epithelial cells and tubular cast formation. (d) - Group IV showing multifocal vacuolation of tubular epithelial cells with some discrete tubular necrosis. (e) - Group V showing diffuse vacuolation of tubular epithelial cells and diffuse tubular necrosis leaving empty spaces. (f) - Group VI showing multifocal vacuolation of tubular epithelial cells and multifocal tubular necrosis. (g) - Group VII showing multifocal vacuolation of tubular epithelial cells. (h) - Group VIII showing multifocal vacuolation of tubular epithelial cells and multifocal tubular necrosis. 


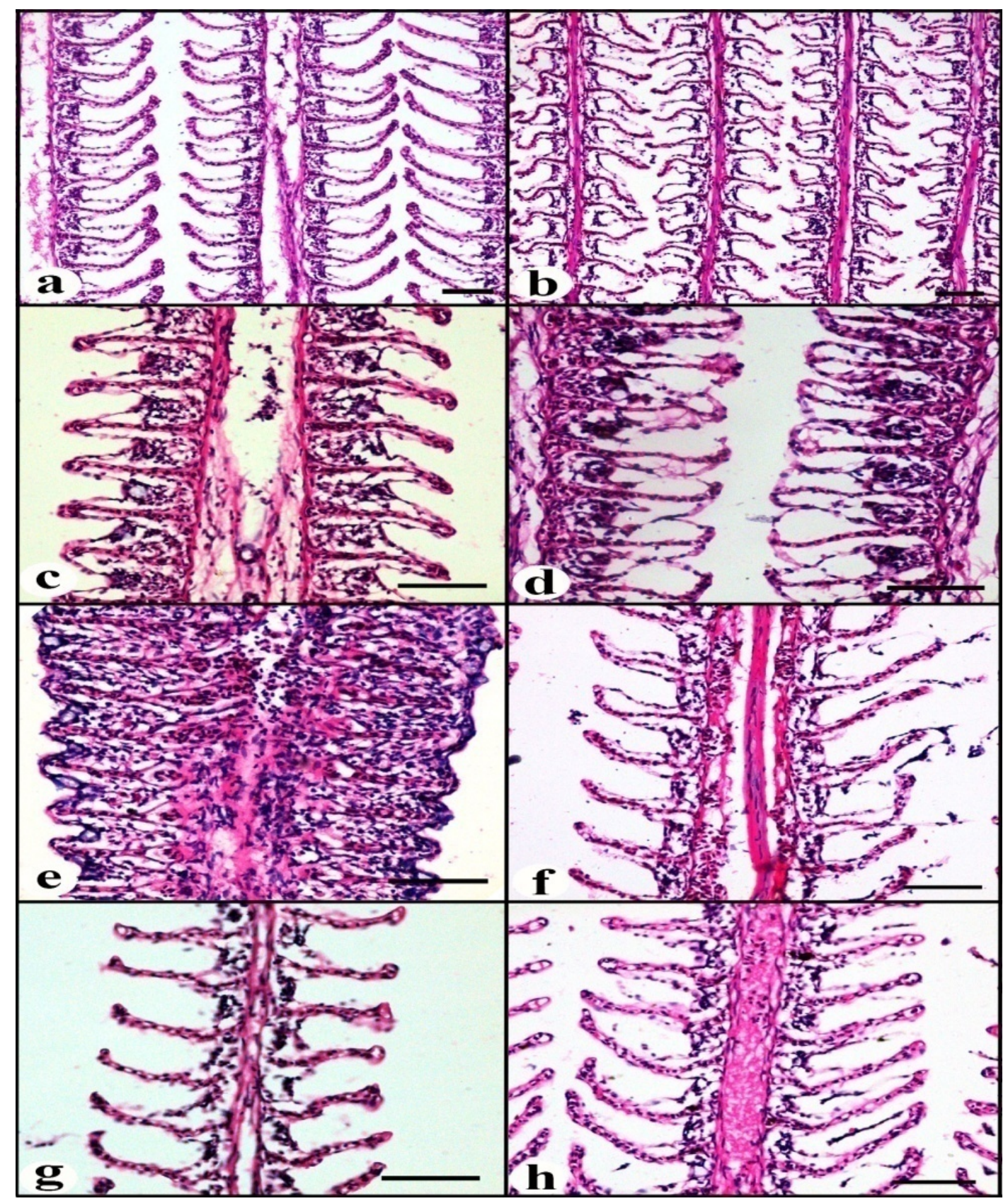

Fig. 3: Photomicrographs of Transverse sections of hepatopancreas of gills O. niloticus (H\&E x 100) (a) - Group I (the control group) showing mild separation in-between the epithelial cell lining of the secondary gill lamellae and the underlying capillary bed. (b) - Group II showing diffuse separation in-between the epithelial cell lining of the secondary gill lamellae and the underlying capillary bed. (c) - Group III showing separation in-between the epithelial cell lining of the secondary gill lamellae and the underlying capillary bed with hyperplasia and necrosis of malpighian cells. (d) - Group IV showing separation in-between the epithelial cell lining of the secondary gill lamellae and the underlying capillary bed with hyperplasia and necrosis of malpighian cells (Spongiosis). (e) - Group V showing congestion of the main lamellar blood vessels with diffuse separation in-between the epithelial cell lining of the secondary gill lamellae and the underlying capillary bed and diffuse hyperplasia of malpighian cells associated with lamellar clubbing. (f) - Group VI showing diffuse separation in-between the epithelial cell lining of the secondary gill lamellae and the underlying capillary bed. (g) - Group VII showing mild separation in-between the epithelial cell lining of the secondary gill lamellae and the underlying capillary bed. (h) - Group VIII showing congestion of the main lamellar blood vessels with mild separation in-between the epithelial cell lining of the secondary gill lamellae and the underlying capillary bed. 


\section{ARABIC SUMMARY}

الدور الوقائى لنيكوتينات النحاس وفيتامين هـ ضد زيت بذور نبات النيم المسبب للاكسدة والتغيرات

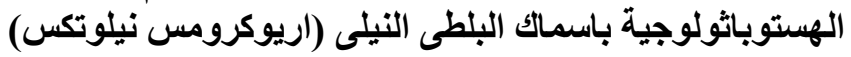

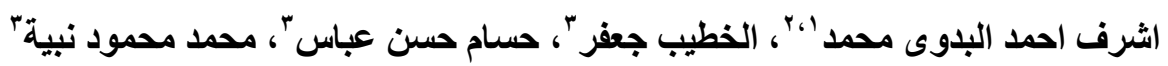

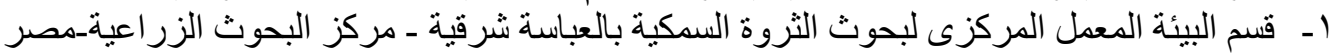

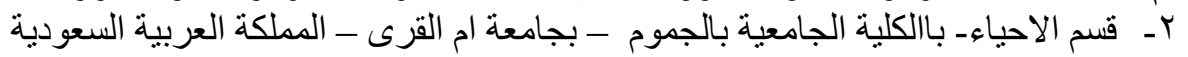

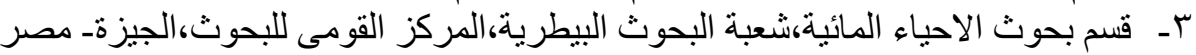

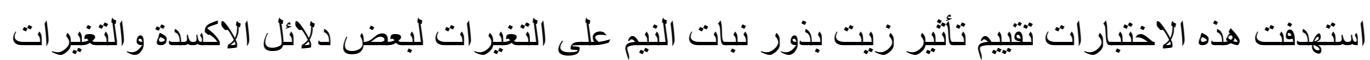

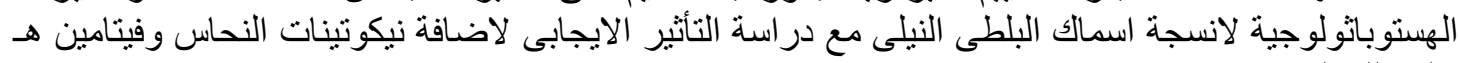

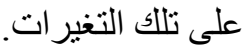

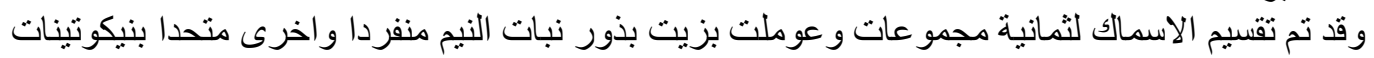
النحاس وفيتامين هـ و اخير ا بالماء النظيف. لأنية.

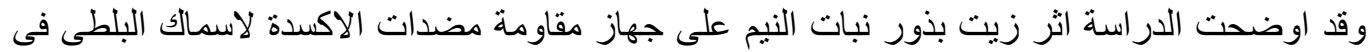

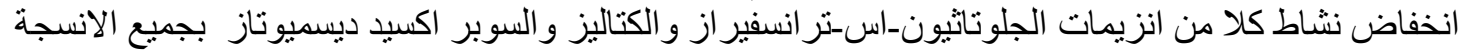
مقارنة بالمجمو عة الضابطة (الكنترول).

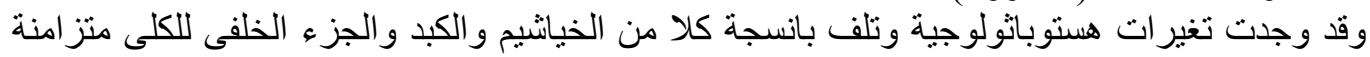

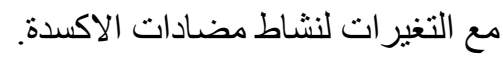

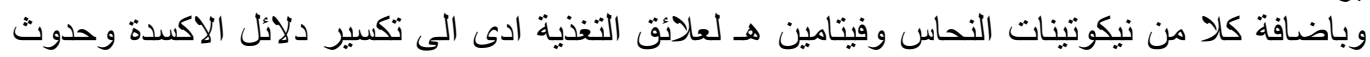

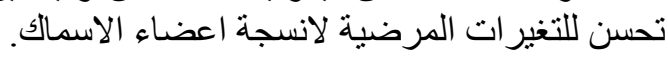

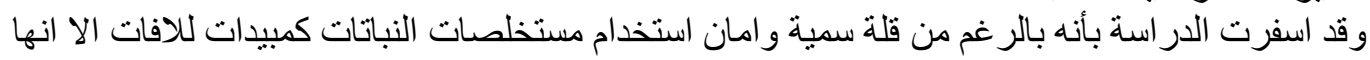

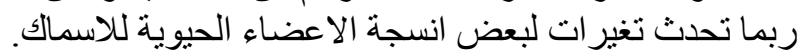
لذا يجب اخذ الاحتياطات اللازمة عند استخدامها اثناء اعداد المستلزمات الخاء الخاصة للانتاج السمكى. 